\title{
Get a HeAd Start! ExPERIENCES OF RUNNING A SUMMER ONLINE CALCUluS COURSE FOR INCOMING FIRST YEAR STUDENTS
}

\author{
Shai Cohen, Micah Stickel \\ Faculty of Applied Science and Engineering, University of Toronto \\ m.stickel@utoronto.ca
}

\begin{abstract}
One of the great advantages of developing online courses is that it enables the institution to reimagine how they can deliver that content to their students. In recent years, the Faculty of Applied Science and Engineering at the University of Toronto has worked to develop a set of first year calculus courses in an online format. These courses were designed specifically for engineering students to: (a) situate the material in an engineering context through multiple real-world examples and "on-site" videos, (b) place an increased emphasis on the form of the solution, and (c) incorporate a significant experience in mathematical modeling through a selfdefined project.
\end{abstract}

In July and August of 2014, the Calculus for Engineers I online course was offered to incoming first-year students that were to start in September 2014. The purpose of this paper is to summarize the experiences related to this unique offering from the perspectives of the students as well as the Faculty administration and course instructor.

Of the 900 students that were invited to take the course, 170 initially registered for the course in early July, and of those 48 students completed the course at the end of August. Of the 44 students that passed the course, $20(48 \%)$ decided to continue on with the online offering of Calculus for Engineers II in the fall 2014 term.

Overall, students were quite positive about their online learning experience and were glad to have the opportunity to complete a credit before their official start. This allowed them to either take an elective in their first year or have a lighter workload in one of the terms.

In their course survey comments, they noted that they appreciated the opportunity to learn and review the material at their own pace, the way in which the instructor connected the mathematics to an engineering context, and having an early introduction to the university learning environment.

Delivering an online university-level calculus course to incoming first-year students is an exciting and novel way to enhance the engineering student experience in first year. This paper provides an introductory summary of this approach from the students', instructor's, and administrators' perspectives.
Keywords: Online teaching, summer bridge programming, first year, mathematics, transition

\section{INTRODUCTION}

Over the past three years the Faculty of Applied Science and Engineering at the University of Toronto has focused significant effort on developing online versions of the core courses within the first-year engineering program. In July and August of 2014, one of these courses, Calculus for Engineers I, was offered to incoming first-year students in order to:

1) Allow students to experience what a universitylevel mathematics course was like,

2) Enable them to complete a program credit before arriving,

3) Allow them the possibility of completing an elective in their first year,

4) Facilitate the transition from their high-school learning approach to one that would help them be successful in the university environment, and

5) Provide a pathway for those students that have had a strong mathematical high-school foundation, such as through IB or AP courses, to demonstrate their understanding at the university level.

While there are many engineering schools that offer summer bridge programs of different varieties, many of these are designed specifically to improve retention and persistence in engineering, see [1] and [2] for example. Often these are geared towards underrepresented minorities within the program, such as those described in [3], [4], and [5].

The purpose of this paper is to share the approach and philosophy behind the course development and the experience associated with this summer online calculus course from the administrators', instructor's, and students' points of view. 


\section{COURSE DEVELOPMENT}

\subsection{Background}

A few pedagogical ideas informed the development of the course. Foremost was the School of One [6]. At the time, this was a pilot project in New York City. Students would come to an after-school program where they would be given the choice of how to learn mathematics individual or group paper work, time with a live online tutor, group instruction, etc. From the success of this program, we found our first axiom: provide the maximum flexibility in teaching methods. These methods are best when connected, but the necessity of any one method should be minimized.

John Mighton's JUMP program was the next major influence [7]. Dr. Mighton insists that when, as educators, we see a student struggle with a new concept, we should always consider this our responsibility and find ways to break down the concept into ever-smaller pieces. Our second axiom was that we needed to find ways to teach each topic - and the subject as a whole - using tools that allow the students to break the math into atomic parts, even without our presence.

A third axiom came from the realization that textbooks and, with them, our teaching, were becoming more modular. Most textbook questions try to isolate the topic presented in that section, trying not to require knowledge from other parts of the book. We wanted to demonstrate and enforce the connections between topics within the course and even between calculus and the other courses in the students' schedules.

Finally, we were concerned about how to prevent students from ignoring their work and then failing the course because they could not catch up quickly. Our final axiom was to create a structure with sufficient rigidity to strongly encourage the students to keep up with the material.

\subsection{Course Design in an Online Format}

We began with an examination of the benefits and limitations of online instruction. What we found is that the most important of these benefits reinforced some of our decisions, but were beyond our ability to use to advantage.

The best aspect of online teaching is the increase in accessibility. Whether an online class is better than, comparable to, or worse than a live class, there are very few subjects in which it is not superior to complete ignorance. We knew that the class would allow us to reach a greater number of students, but this does little to affect its structure.

For the greatest accessibility, it seemed that an asynchronous method of teaching would be best. This is indeed what we chose, but more for pedagogical reasons than anything else. Making videos ahead of time allowed us to edit them and create a more polished product. Generally accepted best practice methods in online education recommend videos of up to ten minutes in length. While there are some notable exceptions to this rule, it seemed to fit in very well with Mighton's philosophy, allowing us to break down a subject into smaller pieces.

Another consequence of this decision was that we were able to create lecture videos - where the material was presented and taught - and example videos - which showed how to use the material within exercises. This gives the students some variety in the methods of study and they can focus on one type of video over another, or (ideally) study from both.

Once accessibility is addressed, the next benefit for students is the ability to pause and rewind. Generally, students think of this ability as a part of "studying at their own pace," which was a reason given by many of them for preferring online classes, but it is quite separate from merely following an individual study plan. To allow a student to stop a video and go back over a section changes the way in which one studies in a fundamental way.

This issue also suggests that the short, asynchronous videos were the best solution. With proper titles and indexing, material will be very easy to find and rewatch.

Finally, online videos allowed us to go beyond the class - whether the classroom or the class materials. We tried to take full advantage of this on a modest budget and tight timeline. Videos went outside of what can be done in a regular classroom wherever the opportunity (and pedagogy) allowed. Annotations were added to the videos, pointing out details that might be missed by the lecture itself, correcting errors, or giving historical details. Occasionally, the videos were filmed "on location," one video showing a race between an instructor and a tortoise, another introducing a topic by bringing in a very large knife and slicing various foods.

We were also able to teach material that does not fit well into regular lectures. A series of videos featuring other members of the faculty (and even one with a professor in kinesiology) show the application of mathematics to various fields. There is a video with advice on how to study for tests and another that gives a design tour of one of the main buildings on campus.

The single most important fact of online teaching is the loss of immediacy - the ability to get instant feedback from the students about the lesson. Even with synchronous teaching, it is exceedingly difficult to get a good sense of the class' level of understanding. The loss of rapport that comes with this changes the dynamic of the class and presents what may be the greatest complaint about online education.

To mitigate the problem, we added to the feedback in the course. We had weekly assignments that were to be written in full. Students were able to hand them in by 
submitting a photo of their page. There was a program used for some mechanical homework to be done, but the assignments themselves were marked using a rubric with the most frequent comments, allowing the TA to give detailed feedback with just a few keystrokes.

A diagnostic test at the beginning of the term allowed us to get the students to understand how well they knew (or, for many, did not know) high-school algebra. Within a week of starting the course, the students were aware of gaps in their understanding of logarithms or absolute values.

Finally, we found that an aspect of immediacy can be addressed in a way that allowed us to work more efficiently. When mistakes were made in the videos, we pointed them out in onscreen text boxes (in one egregious case, we cut in with an explanation of the mistake, filmed weeks later and in another classroom). This showed the students the organic nature of doing mathematics and pointed out that everyone makes mistakes.

Another disadvantage to online classes in the limited interactivity. Questions cannot be asked quite as simply as raising a hand in class, or asking a roommate how they approached an exercise. While there are online features that serve a similar purpose, they do not seem to us to properly substitute for the learning opportunity that comes from sitting around a table with a handful of students from the class, working together on an assignment. Furthermore, mathematical equations are difficult to convey through most forms of online communication, while the fact that students could be spread throughout the world made synchronous options for either group work or instructor help (e.g., Skype) impractical.

We chose the discussion board Piazza as the major tool for personal help in the course. Piazza offered us the ability to compose equations using a good, LaTeX-based editor, the conveniences of a well-designed discussion board, and the ability to communicate across any time difference. Despite these advantages, there were students who complained about the length of time that this took ("There was no prompt help available Piazza was good but could take hours to be answered."), even though email required far more time and online office hours would be offered only at set times.

A decision that seemed to be exceedingly important was for the instructor to spend a lot of time answering questions on the discussion board in the early days of the course. This set the tone for the students for the rest of the course, with the number of postings in the first month of the 48-student course tripling that of its live equivalent from the previous semester, although the latter had ten times as many students. No other decision had helped as much with both the interactive aspect of the course and the lack of immediacy.

\section{SUMMER PRE-ARRIVAL DELIVERY}

\subsection{Administrator's Perspective}

One of the motivating reasons for the running of a summer pre-arrival version of the first calculus course was to help to allay some of the incoming students fears associated with entering university in September. By allowing them to experience a university-level course on material that they already had some exposure to, it was hoped that they would arrive in September with an added degree of comfort and the initial development of successful study skills. However, running of the course presented some interesting logistical challenges that had not been initially anticipated.

The first was related to registering the students in the course, since they were not yet officially students. The second was regarding fees, and the third major challenge was the potential repercussions associated with completing this course.

Both the registration and fees considerations required significant support from the Provost's Office and the associated Faculty and central administration teams. Many meetings with a wide spectrum of people were required, but eventually solutions were found to these problems. The students were registered as non-degree participants and the fees were waived since the cost of the course was essentially already included in their engineering program fees in the upcoming year.

After students completed the course, then some consideration had to be given to how this would impact the rest of their program. How would the mark appear on their transcript? When would they complete the second calculus course? How would they make use of the open spot in their first-year program? What kinds of electives could they take?

It was agreed that the course mark should be counted in their fall term sessional average given the foundational importance of the course. We also wanted to ensure that students could follow up the experience immediately by taking the online version of Calculus for Engineers II in the fall term. Table 1 summarizes the registrations for the course and Table 2 shows the various options of how students who passed the summer online course proceeded in their first year.

From these tables, it can be observed that there was significant interest at the beginning of the course, but only about 5\% (48 out of 900) of the incoming students actually chose to take the course for credit. The gender breakdown was similar to our incoming cohort which had $30.6 \%$ female students in 2014 , yet there were many more students who had been studying abroad that chose to take the summer online course ( $46 \%$ versus a representation of $33.5 \%$ for our incoming class). This might have been due to the increase comfort level with calculus that students who have studied abroad typically develop in high school. 
Table 1: Registration Data Summary.

\begin{tabular}{|l|c|}
\hline \multicolumn{1}{|c|}{ Registration Element } & Number \\
\hline Total Initial Registration & 170 \\
\hline $\begin{array}{l}\text { Total Final Registrations (after the } \\
\text { drop date) }\end{array}$ & 48 \\
\hline $\begin{array}{l}\text { Number of students who passed the } \\
\text { course }\end{array}$ & 44 \\
\hline Percentage of Male Students & $73 \%$ \\
\hline Percentage of Female Students & $27 \%$ \\
\hline Percentage of Domestic Students & $54 \%$ \\
\hline Percentage of International Students & $46 \%$ \\
\hline
\end{tabular}

Table 2: Summary of Student Curricular Pathways.

\begin{tabular}{|l|c|}
\hline \multicolumn{1}{|c|}{ Curricular Pathway } & Number \\
\hline Took online calculus in fall term & $46 \%$ \\
\hline $\begin{array}{l}\text { Took the in-person calculus course in } \\
\text { the winter term }\end{array}$ & $54 \%$ \\
\hline $\begin{array}{l}\text { Took an elective in their fall or } \\
\text { winter term }\end{array}$ & $7 \%$ \\
\hline Took four courses in the fall term & $55 \%$ \\
\hline Took four courses in the winter term & $38 \%$ \\
\hline
\end{tabular}

\subsection{Instructor's Perspective}

The peculiarities of the pre-arrival course forced us to abandon some of the pedagogical structures we had introduced in the previous year. We knew that many students would be spending large sections of the summer at work or on vacation, so we gathered up the assignment deadlines to just two dates - three assignments at the halfway mark and another three at the end of the course.

The assignments still carried voluntary due dates that were spread throughout the semester, but most students ignored these and we ended up with a very limited amount of feedback for the students.

A problem that should have been clear, but was missed until the last moment was that we could not ask questions that connected the course to other courses. The previous offering of the course asked questions that linked to statics and linear algebra, but they could not be used here. We were, however, able to maintain the questions that enforced connections between topics within the course.

Overall, the students were no less mature or prepared than regular incoming students. They tended to work well, but that can be expected from such a self-selected group. For the upcoming summer's offering, we plan to instill a more rigid due date structure without harming students with work or family obligations. Overall, though, the main differences lay more in the condensed timing of the course than in the students' lack of university experience.

\subsection{Students' Perspective}

To gather the perspective from students a 9-question survey was sent to them at the end of the Winter 2015 term. Of the 48 students that registered in the course, 21 students responded (44\% response rate). The first 5 questions asked them to agree or disagree to a statement relating to their course and first-year experience and these are summarized in Table 3 below.

Overall, students responded quite positively with $96 \%$ agreeing that the course was an effective learning experience and $81 \%$ indicating that it prepared them well for their other first-year courses. A smaller percentage of students found that the experience helped them to develop the skills needed to be successful in their first year, and perhaps this was because no specific discussion or effort was made in this course to address this topic directly. While $76 \%$ of the students found that by taking the course their workload was less than they had expected, 24\% felt quite strongly that their workload was not at all easier than they had anticipated. This might be that they had an unrealistic view of the requirements of their first-year program, or that 3 of these 5 "strongly-disagree" respondents were the students that took electives in first year.

Students were also asked to share their thoughts on an unexpected benefit and disadvantage in taking this summer online calculus course. Some of the representative comments regarding benefits included:

"Recognizing when professors use calculus in your first term classes."

"A professor who connects concepts in the course to other classes with ease is worth our tutiton!"

"As an international student, I got used a bit to lectures in english and learned many math terms in English; I got an idea of how my workload is going to be, and how different is it going to be from school 'study style'."

"Giving me time to really work out the material. I didn't realize how little time I'd dedicate to each course once the semester started."

"Saved from the stress of two term tests and finals!"

"My ability to apply calculus to the real world has greatly increased"

"Learned how Blackboard (LMS) works"

"Gave knowledge about calculus before the term began and so, created a base for understanding other course materials." 
Table 3: Student Survey Response Summary - Course and First-Year Experience.

\begin{tabular}{|c|c|c|c|c|}
\hline Statement & $\begin{array}{l}\text { Strongly } \\
\text { Disagree }\end{array}$ & Disagree & Agree & Strongly Agree \\
\hline $\begin{array}{l}\text { The course was an effective learning } \\
\text { experience. }\end{array}$ & $0 \%$ & $5 \%$ & $48 \%$ & $48 \%$ \\
\hline $\begin{array}{l}\text { That the course prepared me well for my } \\
\text { other courses in first year. }\end{array}$ & $0 \%$ & $19 \%$ & $52 \%$ & $29 \%$ \\
\hline $\begin{array}{l}\text { That by taking the course my transition } \\
\text { into first year was easier than expected. }\end{array}$ & $0 \%$ & $14 \%$ & $48 \%$ & $38 \%$ \\
\hline $\begin{array}{l}\text { That the experience helped me to develop } \\
\text { the skills needed to be successful in my } \\
\text { other first year courses. }\end{array}$ & $0 \%$ & $38 \%$ & $48 \%$ & $14 \%$ \\
\hline $\begin{array}{l}\text { That by taking the course my first year } \\
\text { workload was easier than I had expected. }\end{array}$ & $24 \%$ & $0 \%$ & $52 \%$ & $24 \%$ \\
\hline
\end{tabular}

Some comments regarding disadvantages were:

"I forgot some of the material by the second semester: I wanted to take Calculus II in real life, and it was only available during second semester. But, to be honest, it was not that much of a problem in comparison of how useful the course was."

"There was no prompt help available Piazza was good but could take hours to be answered"

"It was more difficult to get instructor feedback."

"If you're really stuck on a problem, support options are limited.”

"Didn't learn as much as I think I would have if I did the course in person"

Finally, students were asked to comment on what they most appreciated about having taken this course in the summer and what changes they would suggest. For the things that students appreciated, they commented:

"I had already studied most of the material, so I appreciated that I could go at my own pace."

"I can skip contents I have learned before without feeling guilty."

"Freedom to work at my own pace and focus on topics I was having trouble with before moving on to next chapter."

For suggested improvements:

"Maybe make the final project less vague? I understand that it leaves some room for creativity, but for me it was the most confusing part of the course"

"To have a weekly checkpoint list that interactively records whether the student has watched the video, etc to show a real-time progress check."
"To gain feedback faster for assignments so the same mistakes we made on one assignment are not repeated in the later assignments."

"Offering some form of 'Office Hours' over Skype."

\section{CONCLUSIONS}

This paper has summarized the students', instructor's, and administrators' perspective on the delivery of an online summer bridge calculus course for incoming firstyear engineering students.

It was found that out of the 900 students who were invited to take the course, 170 initially signed up and then 48 ended up completing the course. For the 44 students that passed the course, $48 \%$ decided to take the follow-up Calculus for Engineers II course in an online format in the fall term. The rest $(52 \%)$ waited until the winter term to take Calculus II in a face-to-face course. Only three of the 44 students decided to take an elective in the first year, with the remaining group opting to take a lighter load ( 4 courses) in either the fall or winter term.

Two major items were identified by the instructor relating to the differences in teaching this course during the pre-arrival time. First, the assessment deadlines needed to be more flexible given these students' unique work, personal, and family obligations during this time. Second, since the course was delivered in isolation from any of the other core engineering courses, examples and problems that would typically link these courses together had to be modified or not used at all.

Overall, the students were quite positive about the course, with $81 \%$ of the 21 survey respondents $(44 \%$ response rate) agreed that it prepared them well for their other first-year courses, and $86 \%$ felt that by taking the course in the summer it make their first-year workload easier than expected. Fewer students $(62 \%)$ agreed that it helped them to develop skills needed to be successful in first year, and $24 \%$ strongly disagreed with the notion that 
their first-year workload was easier than expected having taking this summer online course.

Students' comments indicated that they most appreciated the ability to learn the material at their own pace, that the mathematical material was contextualized through engineering examples and a modeling exercise, that the course allowed them to get comfortable with the engineering academic environment, and that it gave them more flexibility in their first-year program.

Students also suggested that greater efforts be made to guide and support students through the course through improved timely feedback on assignments, regular checkpoints, and online tutorials or individual office hours. They did note that the lack of direct contact with their instructor was frustrating at times during their learning process.

This course and its delivery at this unique time will continue to be developed over the years to come. Efforts will be made to improve the student learning experience through more timely feedback and instructor availability, while at the same time being more explicit about supporting students in their transition into the engineering academic environment.

\section{References}

[1] J. Gleason, K. Boykin, P. Johnson, L. Bowen, K. Whitaker, C. Micu, D. Raju and C. Slappy, "Integrated engineering math-based summer bridge program for student retention," Advances in Engineering Education, vol. 2, no. 2, pp. 1-17, 2010.

[2] J. M. Raines, "FirstSTEP: A preliminary review of the effects of a summer bridge program on pre-college STEM majors," Journal of STEM Education: Innovations and Research, vol. 13, no. 1, pp. 22-29, 2012.

[3] S. L. Fletcher, D. C. Newell, L. D. Newton and M. R. Anderson-Rowland, "The WISE Summer Bridge Program: assessing student attrition, retention, and program effectiveness," in In Proceedings, American Society for Engineering Education, 2001.

[4] G. S. May and D. E. Chubin, "A retrospective on undergraduate engineering success for underrepresented minority students," Journal of Engineering Education, vol. 92, no. 1, pp. 27-39, 2003.

[5] H. M. Doerr, J. B. Ärlebäck and A. Costello Staniec, "Design and effectiveness of modeling-based mathematics in a summer bridge program," Journal of Engineering Education, vol. 103, no. 1, pp. 92-114, 2014.

[6] "The School of One," iZone, [Online]. Available: http:// izonenyc.org/initiatives/school-of-one/. [Accessed 18 April 2015].

[7] "JUMP Math," [Online]. Available: http://www.jumpmath.org/. [Accessed 18 April 2015]. 